\title{
Moisture absorption behavior of stressed and unstressed E-Glass epoxy composites under varying conditions of temperature
}

\begin{abstract}
In order to meet the market demands the practitioners are searching for light weight and higher strength materials at lower cost. In this context, the mechanical and structural properties of fibre reinforced plastic (FRP) satisfy the market demands and has been used worldwide for many industrial applications. But in the due course of time a composite part behaves like a sponge and absorbs moisture which leads to increase in weight and degradation of mechanical properties. This loss in mechanical properties may be due to plasticization of matrix by water and degradation of fiber-matrix interfacial bond. Hence the present study analyses the moisture absorption behavior of E-Glass epoxy Inter Laminar Shear Strength (ILSS) stressed and unstressed specimens of fiber weight fraction 60:40.
\end{abstract}

Keywords: E-glass fibres, polymer matrix composites, moisture absorption behaviour
Volume 2 Issue 8 - 2017

\section{Saravanan R \\ Department of Mechanical Engineering, University Visvesvaraya College of Engineering, India}

Correspondence: Saravanan R, Department of Mechanica Engineering, University Visvesvaraya College of Engineering, India, Email rsaravanan72@yahoo.com

Received: February 28, 2017 | Published: December 27, 2017

\section{Introduction}

Since the composites are exposed to different types of environment continuously, it is necessary for the designers to know as much as possible, about the properties of materials they use. Though the initial properties of composites are reasonably well, they do not remain constant forever. Deterioration takes place sooner or later depending on the environment they are exposed to. Composites are exposed to different types of environments such as ultraviolet radiation, low/ high temperatures, and humidity (dry and wet). All these factors tend to degrade the composites' structural integrity in several ways that ultimately reduce their service life. Of these factors, humidity has been recognized to be the most detrimental factors affecting the composites performance. Moisture can penetrate the composite structure sufficiently to cause degradation effects ranging from a temporary loss of composite strength to a total or catastrophic breakdown of the composite structure.

Ideally composites are light-weight, strong and corrosion resistant. But over a long period of time a composite part behaves like a sponge and absorbs moisture which leads to increase in weight and degradation of mechanical properties. This loss in mechanical properties may be due to plasticization of matrix by water and degradation of fiber-matrix interfacial bond. The moisture absorption characterization of polymer composites is broadly governed by internal and external factors. The most important internal factors are micro-voids, cracks, molecular holes, fiber orientation angle, fiber volume fraction and fiber nature. The most important external factors are fluids, radiation, hailstones, ambient temperature, relative humidity and erosion; of these the most important are temperature and relative humidity.

Blaga \& Yamasaki $^{1}$ reported for the first time, the physical deterioration of glass fiber reinforced polyester composites subjected to cyclic variations in moisture, temperature and radiation. Wright et $\mathrm{al}^{2}{ }^{2}$ noted that the absorbed moisture in epoxy composites caused dimensional changes and internal stresses leading to inferior mechanical properties. Ray $^{3}$ concluded that inter laminar shear stresses is one of the important failure phenomenon dependent on the adhesiveness of the epoxy bond energies cross linkages and molecular orientations. Springer ${ }^{4}$ noted that the moisture absorption of polymer composites changed considerably when they were exposed to sudden and large temperature variations $(200-400 \mathrm{~K})$. Sottos et al. ${ }^{5}$ reviewed the literature on aging of plastics and reported that the type of resin often governed the initial weathering effects as well as rate of moisture absorption. They noted that the flexible resins were generally less resistant to weathering than the rigid ones. Accordingly, the flexible resins were noted to absorb high amounts of water and exhibited poor weather resistant characteristics. Against this background after a careful analysis of various research studies conducted so far it has been observed that there is an insufficiency of literature in the moisture absorption studies of composites. Hence the present study analyses the moisture absorption behavior of E-Glass epoxy Inter Laminar Shear Strength (ILSS) stressed and unstressed specimens of fiber weight fraction 60:40.

\section{Methodology}

E-Glass ILSS stressed and unstressed specimens of fiber weight fraction $60: 40\left(\mathrm{~W}_{2}\right)$ after exposure to $55^{\circ} \mathrm{C}$ and $-18^{\circ} \mathrm{C}$ were removed for subsequent period and immersed in distilled water bath at $50^{\circ} \mathrm{C}$. To study the moisture absorption behavior, specimens were placed in a constant temperature distilled water bath maintained at $50^{\circ} \mathrm{C}$ after taking its initial dry weights. The specimens were periodically taken out from the water bath to measure their weight gain as outlined below:

i. The specimens were first taken out of the bath and were placed on a filter paper. Each specimen was wiped with the filter paper to remove the free moisture adhering to its surfaces as well as the edges.

ii. The wiped specimens were weighed on an electronic balance and immediately returned to the water bath. This was done in order to minimize any possible loss of moisture from the specimen at room temperature conditions. 
iii. The measured weights of the wet specimen were tabulated along with the square root of immersion time.

iv. The percentage moisture gain by the specimen was calculated by the equation as follows: $\mathrm{M}=\left(\mathrm{W}-\mathrm{W}_{\mathrm{d}}\right) /\left(\mathrm{W}_{\mathrm{d}}\right) * 100$ where $\mathrm{W}=$ Weight of moist specimen, $\mathrm{W}_{\mathrm{d}}=$ Weight of dry specimen.

The percentage moisture gain by the specimen was plotted as a function of square root of immersion time (in hours).

\section{Results and discussions}

a. Moisture gain (\%) values generated for specimens of $\mathrm{W}_{2}$ at room temperature are indicated in Table 1.

b. From the Table 2 Moisture gain (\%) value generated for stressed and unstressed specimens of $\mathrm{W}_{2}$ (exposed to $+55^{\circ} \mathrm{C} \pm 2^{\circ}$ for 1 week), it is inferred that for the stressed specimen, the initial rate of moisture absorption and maximum moisture content is higher than that of unstressed specimen.

c. From the Table 3 Moisture gain (\%) value generated for stressed and unstressed specimens of $\mathrm{W}_{2}$ (exposed to $+55^{\circ} \mathrm{C} \pm 2^{\circ}$ for 2 weeks), it is inferred that for the stressed specimen the initial rate of moisture absorption and maximum moisture content is higher than that of unstressed specimen.

d. From the Table 4 Moisture gain (\%) value generated for stressed and unstressed specimens of $\mathrm{W}_{2}$ (exposed to $-18^{\circ} \mathrm{C} \pm 3^{\circ}$ for 1 week) it is inferred that for the stressed specimen the initial rate of moisture absorption and maximum moisture content is higher than that of unstressed specimen. e. From the Table 5 Moisture gain (\%) value generated for stressed and unstressed specimens of $\mathrm{W}_{2}$ (exposed to $-18^{\circ} \mathrm{C} \pm 3^{\circ}$ for 2 weeks) it is inferred that for the unstressed specimen the initial rate of moisture absorption is higher than that of stressed specimen but maximum moisture content of stressed specimen is higher than the unstressed specimen.

Table I Moisture gain (\%) and Sqrt time (hrs) for specimens of $\mathrm{W}_{2}$ at room temperature immersed in distilled water at $50^{\circ} \mathrm{C}$

\begin{tabular}{lll}
\hline Time (hrs) & Sqrt (Time) & Average moisture gain (\%) \\
\hline 0 & 0 & 0 \\
24 & 4.89 & 0.435 \\
48 & 6.92 & 0.755 \\
120 & 10.95 & 1.109 \\
264 & 16.24 & 1.197 \\
312 & 17.66 & 1.285 \\
336 & 18.33 & 1.373 \\
648 & 25.45 & 1.431 \\
768 & 27.71 & 1.489 \\
840 & 28.98 & 1.547 \\
1008 & 31.74 & 1.606 \\
1344 & 36.66 & 1.617 \\
1512 & 38.88 & 1.619 \\
\hline
\end{tabular}

Table 2 Moisture gain (\%) and exposure time (hrs) for stressed and unstressed specimens of $\mathrm{W}_{2}$ (exposed to $+55^{\circ} \mathrm{C} \pm 2^{\circ}$ for I week) immersed in distilled water at $50^{\circ} \mathrm{C}$

\begin{tabular}{llll}
\hline $\begin{array}{l}\text { Time } \\
\text { (hrs) }\end{array}$ & $\begin{array}{l}\text { Sqrt time } \\
\text { (hrs) }\end{array}$ & $\begin{array}{l}\text { Average moisture gain (\%) of stressed } \\
\text { specimen }\end{array}$ & $\begin{array}{l}\text { Average moisture gain (\%) of unstressed } \\
\text { specimen }\end{array}$ \\
\hline 0 & 0 & 0 & 0 \\
24 & 4.89 & 0.248 & 0.194 \\
48 & 6.92 & 0.652 & 0.553 \\
144 & 12 & 0.773 & 0.699 \\
216 & 14.69 & 0.859 & 0.794 \\
336 & 18.33 & 0.958 & 0.9 \\
408 & 20.19 & 1.013 & 0.956 \\
528 & 22.97 & 1.09 & 1.062 \\
576 & 24 & 1.174 & 1.101 \\
\hline
\end{tabular}

Table 3 Moisture gain (\%) v/s exposure time (hrs) for stressed and unstressed specimen of $\mathrm{W}_{2}$ (exposed to $+55^{\circ} \mathrm{C} \pm 2^{\circ}$ for 2 weeks) immersed in distilled water at $50^{\circ} \mathrm{C}$

\begin{tabular}{llll}
\hline $\begin{array}{l}\text { Time } \\
(\mathrm{hrs})\end{array}$ & $\begin{array}{l}\text { Sqrt time } \\
\text { (hrs) }\end{array}$ & $\begin{array}{l}\text { Average moisture gain (\%) of stressed } \\
\text { specimen }\end{array}$ & $\begin{array}{l}\text { Average moisture gain (\%) of unstressed } \\
\text { specimen }\end{array}$ \\
\hline 0 & 0 & 0 & 0 \\
24 & 4.89 & 0.244 & 0.19 \\
48 & 6.928 & 0.602 & 0.46 \\
144 & 12 & 0.768 & 0.655 \\
\hline
\end{tabular}


Table Continued...

\begin{tabular}{llll}
\hline $\begin{array}{l}\text { Time } \\
(\mathbf{h r s})\end{array}$ & $\begin{array}{l}\text { Sqrt time } \\
\text { (hrs) }\end{array}$ & $\begin{array}{l}\text { Average moisture gain (\%) of stressed } \\
\text { specimen }\end{array}$ & $\begin{array}{l}\text { Average moisture gain (\%) of unstressed } \\
\text { specimen }\end{array}$ \\
\hline 216 & 14.69 & 0.832 & 0.734 \\
336 & 18.33 & 0.921 & 0.835 \\
408 & 20.19 & 0.984 & 0.898 \\
528 & 22.97 & 1.111 & 1.024 \\
576 & 24 & 1.13 & 1.08 \\
\hline
\end{tabular}

Table 4 Moisture gain (\%) and exposure time (hrs) for stressed and unstressed specimens of $W_{2}$ exposed to $-18^{\circ} \mathrm{C} \pm 3^{\circ}$ for $I$ week

\begin{tabular}{llll}
\hline $\begin{array}{l}\text { Time } \\
(\mathbf{H r s})\end{array}$ & $\begin{array}{l}\text { Sqrt time } \\
\text { (Hrs) }\end{array}$ & $\begin{array}{l}\text { Average moisture gain (\%) of stressed } \\
\text { specimen }\end{array}$ & $\begin{array}{l}\text { Average moisture gain (\%) of unstressed } \\
\text { specimen }\end{array}$ \\
\hline 0 & 0 & 0 & 0 \\
24 & 4.89 & 0.200 & 0.163 \\
48 & 6.92 & 0.487 & 0.408 \\
144 & 12 & 0.643 & 0.539 \\
216 & 14.69 & 0.751 & 0.587 \\
336 & 18.33 & 0.779 & 0.635 \\
408 & 20.19 & 0.838 & 0.679 \\
528 & 22.97 & 0.95 & 0.797 \\
576 & 24 & 0.992 & 0.861 \\
\hline
\end{tabular}

Table 5 Moisture gain (\%) v/s exposure time (hrs) for stressed and unstressed specimens of $\mathrm{W}_{2}$ (exposed to $-18^{\circ} \mathrm{C} \pm 3^{\circ}$ for 2 weeks)

\begin{tabular}{llll}
\hline $\begin{array}{l}\text { Time } \\
(\mathbf{h r s})\end{array}$ & $\begin{array}{l}\text { Sqrt time } \\
(\mathbf{h r s})\end{array}$ & $\begin{array}{l}\text { Average moisture gain (\%) of stressed } \\
\text { specimen }\end{array}$ & $\begin{array}{l}\text { Average moisture gain (\%) of unstressed } \\
\text { specimen }\end{array}$ \\
\hline 0 & 0 & 0 & 0 \\
24 & 4.89 & 0.172 & 0.202 \\
48 & 6.92 & 0.438 & 0.522 \\
144 & 12 & 0.598 & 0.584 \\
216 & 14.69 & 0.667 & 0.669 \\
336 & 18.33 & 0.765 & 0.767 \\
408 & 20.19 & 0.831 & 0.798 \\
528 & 22.97 & 0.885 & 0.899 \\
576 & 24 & 1.006 & 0.949 \\
\hline
\end{tabular}

\section{Conclusion}

i. The present study has analyzed the moisture absorption behavior in E-Glass ILSS stressed and unstressed specimens of fiber weight fraction 60:40 and the results are discussed.

ii. The study can be further continued under different operating conditions.

\section{Acknowledgements}

The present work thanks the support rendered by L. Surya Narayanan who has undertaken this study.

\section{Conflict of interest}

The author declares no conflict of interest.

\section{References}

1. Blaga A, Yamasaki RS. Mechanism of breakdown in the interface region of glass reinforced polyester by artificial weathering. Journal of Material Science. 1973;8(5):654-666.

2. Wright, Sutherland LS, Soares Guedes C. Effect of laminate thickness and of matrix resin on the impact of low-fiber volume woven roving E-Glass composites. Composite Science and Technology. 2004;64(1011):1691-1700. 
3. Ray BC. Adhesion of Glass/Epoxy Composites Influenced by Thermal and Cryogenic Environments. Journal of Applied Polymer Science. 2006;102(2):1943-1949.

4. Springer GS. Environmental effects on epoxy matrix composites, ASTM Conference on composites material-design and testing. New Orleans. USA; 1978. p. 1-26.
5. Sottos N, Hiemdtra DL, Scott WR. Correlating Interphase Glass Transition and Interfacial Microcraking in Polymer Composites. Fracture mechanics. 1994;25:1220. 